\title{
Outcomes of Early Laparoscopic Cholecystectomy in Acute Cholecystitis
}

\author{
Dr. R. Talukdar", Dr. Uma Pradhan, Dr. Ravi Kumar, Dr. P.N. Agarwal, Dr. Aparajita Singh
}

S.G.T. University, Faculty of Medical and Health Sciences, Budhera, Gurugram, Haryana, India

DOI: $10.36347 /$ sasjs.2021.v07i01.003

| Received: 26.12.2020 | Accepted: 11.01.2021 | Published: 14.01.2021

*Corresponding author: Dr. R. Talukdar

\section{Abstract}

Original Research Article

The optimal timing to perform cholecystectomy in patients with acute cholecystitis remains controversial. Many surgeons prefer interval cholecystectomy over early and believe it to be safer for patient and easier for the surgeon. There are many studies over no difference in outcome of early cholecystectomy with respect to interval cholecystectomy in patients of acute cholecystitis. The aim of this study is to assess outcome of early laparoscopic cholecystectomy (ELC) for acute cholecystitis in a rural setup. The series consisted of 50 patients who underwent ELC for acute cholecystitis from June 2017 to December 2020. Multiple parameters like hospital stay, duration of surgery, conversion to open cholecystectomy, cost effectiveness were assessed for these patients post operatively. Our study confirms that early cholecystectomy in acute cholecystitis does not increase morbidity in patient and is as safe as delayed cholecystectomy.

Keywords: Acute Cholecystitis, Laparoscopic Cholecystectomy, Early Cholecystectomy, Delayed Cholecystectomy. Copyright $\odot 2021$ The Author(s): This is an open-access article distributed under the terms of the Creative Commons Attribution 4.0 International License (CC BY-NC 4.0) which permits unrestricted use, distribution, and reproduction in any medium for non-commercial use provided the original author and source are credited.

\section{INTRODUCTION}

Acute cholecystitis is a possibly lifethreatening condition, which affects approximately 20 million Americans yearly and causes high economic burden around the world [1]. Early laparoscopic cholecystectomy (ELC) is principal approach for treating acute cholecystitis nowadays [2]. Although LCs have been considerably performed to manage acute cholecystitis, the optimal timing of LC for this given condition is still not conclusive.

Traditionally, given the higher rate of morbidity such as bile duct injury, leakage, and conversion to open surgery, the delayed LC (DLC) was preferred [3]. Early cholecystectomy performed within 7 days of the onset of the illness is now preferred over delayed cholecystectomy that is performed 6 to 10 weeks after initial medical treatment and recuperation. Several studies have shown that unless the patient is unfit for surgery, early cholecystectomy should be recommended as soon as possible, as it offers the patient a definitive solution in one hospital admission, quicker recovery times, similar complication rates, and an earlier return to work [4-8]. Although some systematic reviews with meta-analysis investigated the optimal timing of LC for patients with acute cholecystitis previously, a consistent and conclusive conclusion has not yet been obtained from these systematic reviews.

\section{METHODOLOGY}

It was a prospective and descriptive study spread over a period of 30 months (July 2017 to December 31, 2020) and carried out by General Surgery Department at S.G.T. Hospital, Chandu- Budhera, Gurugram. It concerned all patients admitted to hospital diagnosed as a case of acute cholecystits on ultrasonography. The indicators for acute cholecystits on ultrasound were gallbladder wall thickening and pericholecystic fluid, Focal tenderness over the gallbladder when compressed by the sonographic probe (sonographic Murphy's sign). Our data were collected on the basis of surgical files and postoperative care files. The variables measured were: difference in mortality, bile duct injury, bile leakage, overall complications, and conversion to open surgery, wound infection, hospitalization, and operation duration and improvement of the quality of life, number of work days lost, hospital costs, and patient satisfaction. SPSS 12.0 software was used for data entry and analysis.

\section{RESULTS}

During the period of our study, 50 patients were presented with acute cholecystitis, including 12 males and 38 females. The 30-50 age group was the most represented. On examination, the majority of patients were in good general condition. Table- 1 shows variation of patient data. 
Table-1: Parameters of the patients

\begin{tabular}{|l|l|}
\hline Age & 47 \\
\hline Sex (female) & $76 \%$ \\
\hline Previous history & $64 \%$ \\
\hline Duration of symptoms & $2.4 \pm 1.5$ \\
\hline Increased risk & $44 \%$ \\
\hline Deranged LFTs & 2 \\
\hline
\end{tabular}

The morbidity in ELC included surgical site infection, bleeding, bile duct injury was found to be $12 \%$. Bleeding from the liver bed and due to cystic artery injury was seen in 4 patients which was controlled intra- operatively with addition of subhepatic drain placement. Total 5 patients had surgical site infection, 2 of those who had conversion to open procedure and 3 of laparoscopic cholecystectomy. The average time taken was 37.5 mins. 4 females had previous history of tubectomy and had infra- umblical scar, so, placement of umbilical port was done by open technique.

There was no mortality in intra or post operative period and no patient required ICU stay.

Average hospital stay was 3.2 days. Only the patients who needed conversion were in the hospital for 5-7 days. All other patients were discharged within 3 days. One patient required readmission for surgical site infection with uncontrolled diabetes after conversion. There was no CBD / GIT injury.

Table-2: Outcomes

\begin{tabular}{|l|l|}
\hline Surgical site infection & 5 \\
\hline Bleeding & 4 \\
\hline Total time taken & 37.5 mins \pm 12.4 mins \\
\hline Previous scar & 4 \\
\hline Mortality & 0 \\
\hline ICU Stay & 0 \\
\hline Average hospital stay & 3.2 \\
\hline CBD/GIT injury & 0 \\
Conversion to open & 4 \\
\hline
\end{tabular}

\section{DISCUSSION}

This study has found no significant increase in the proportion of patients with complications or conversion to open cholecystectomy whether laparoscopic cholecystectomy is performed within 7 days of acute cholecystitis or six to 12 weeks after the symptoms settle. Early surgery has the advantage of decreased hospital stay and avoids the risk of emergency surgery for unresolved or recurrent symptoms which may result in high rate of conversion to open cholecystectomy. Bile duct injury is the most devastating complication during cholecystectomy and can be fatal [9]. Cholecystitis has been considered as a risk factor for bile duct injury [10, 11]. Larger studies will be required to show the small differences in bile duct injury rates between an early or delayed approach to acute cholecystitis.
There was no significant increase in the other serious complications related to surgery. There was also no significant increase in the proportion of people who required conversion to open surgery.

While there are reports of an increased proportion of conversion to open cholecystectomy when the cholecystectomy is delayed for more than 48 to 96 hours after the onset of symptoms [12-15], there are also studies that do not confirm this $[16,17]$.

The total hospital stay of the participants is short. There is usually a longer hospital stay for delayed cholecystectomy due to requirement two treatment episodes, one for the conservative treatment of acute cholecystitis and another for the definitive surgical treatment.

In addition, in the delayed group nonresolution or recurrent cholecystitis may require urgent surgery or readmission due to recurrent symptoms.

Another important issue is gallstone-related morbidity during the waiting period for cholecystectomy.

Early Laparoscopic cholecystectomy performed by experienced General surgeons or upper gastrointestinal (upper GI) surgeons has lower conversion to open cholecystectomy rates and shorter hospital stay [18]. Early laparoscopic cholecystectomy should therefore be performed in units with appropriate surgical expertise.

The recommendation from that study, therefore, was that a policy of early laparoscopic cholecystectomy should be employed for acute colecystitis when performed by surgeon with expertise.

\section{CONCLUSION}

In conclusion, we demonstrated that early laparoscopic cholecystectomy had no increased complication and is superior to delayed cholecystectomy in terms of a reduced total length of hospital stay. Laparoscopic cholecystectomy is a safe and cost-effective approach for the management of acute cholecystitis. This approach averts the risk of recurrent attack or the development of other biliary complications while the patients are awaiting definitive surgical intervention.

\section{REFERENCES}

1. Strasberg SM. Clinical practice. Acute calculous cholecystitis. N Engl J Med. 2008;358:2804-11.

2. Menahem B, Mulliri A, Fohlen A, Guittet L, Alves A, Lubrano J. Delayed laparoscopic cholecystectomy increases the total hospital stay compared to an early laparoscopic cholecystectomy after acute cholecystitis: an 
R. Talukdar et al., SAS J Surg, Jan, 2021; 7(1): 8-10

updated meta analysis of randomized controlled trials. HPB. 2015 Oct 1;17(10):857-62.

3. Gomi H, Solomkin JS, Takada T, Strasberg SM, Pitt HA, Yoshida M, Kusachi S, Mayumi T, Miura F, Kiriyama S, Yokoe M. TG13 antimicrobial therapy for acute cholangitis and cholecystitis. Journal of hepato-biliary-pancreatic sciences. 2013 Jan 1;20(1):60-70.

4. Jarvinen HJ, Hastbacka J. Early cholecystectomy for acute cholecystitis: a prospective randomized study. Ann Surg. 1980;191:501.

5. Lahtinen J, Alhava EM, Aukee S. Acute cholecystitis treated by early and delayed surgery. A controlled clinical trial. Scand J Gastroenterol. 1978;13:673-8.

6. Yadav RP, Adhikary S, Agrawal CS, Bhattarai B, Gupta RK, Ghimire A. A comparative study of early vs. delayed laparoscopic cholecystectomy in acute cholecystitis. Kathmandu University medical journal. 2009;7(1):16-20.

7. Hunter JG. Acute cholecystitis revisited: get it while it's hot. Ann Surg. 1998;227(4):468-469.

8. Ansaloni L, Pisano M, Coccolini F, Peitzmann AB, Fingerhut A, Catena F, Agresta F, Allegri A, Bailey I, Balogh ZJ, Bendinelli C. 2016 WSES guidelines on acute calculous cholecystitis. World journal of emergency surgery. 2016 Dec 1;11(1):25.

9. Sicklick JK, Camp MS, Lillemoe KD, Melton GB, Yeo CJ, Campbell KA, Talamini MA, Pitt HA, Coleman J, Sauter PA, Cameron JL. Surgical management of bile duct injuries sustained during laparoscopic cholecystectomy: perioperative results in 200 patients. Annals of Surgery. 2005 May;241(5):786.

10. Richardson MC, Bell G, Fullarton GM. Incidence and nature of bile duct injuries following laparoscopic cholecystectomy: an audit of 5913 cases. British Journal of Surgery. 1996;83(10):1356-60.

11. Nuzzo G, Giuliante F, Giovannini I, Ardito F, D’Acapito F, Vellone M. Bile duct injury during laparoscopic cholecystectomy: results of an Italian national survey on 56591 cholecystectomies. Archives of Surgery. 2005;140(10): 986-92.

12. Eldar S, Sabo E, Nash E, Abrahamson J, Matter I. Laparoscopic cholecystectomy for acute cholecystitis: prospective trial. World Journal of Surgery. 1997;21(5):540-5.

13. Madan AK, Aliabadi-Wahle S, Tesi D, Flint LM, Steinberg SM. How early is early laparoscopic treatment of acute cholecystitis?. American Journal of Surgery 2002;183(3):232-6.

14. Liguori G, Bortul M, Castiglia D. The treatment of laparoscopic cholecystectomy for acute cholecystitis [Il trattamento della colecistite acuta in era laparoscopica]. Annali Italiani Di Chirurgia. 2003;74(5):517-21

15. Peng WK, Sheikh Z, Nixon SJ, Paterson-Brown S. Role of laparoscopic cholecystectomy in the early management of acute gallbladder disease. British Journal of Surgery. 2005;92:586-91.

16. Chandler CF, Lane JS, Ferguson P, Thompson JE, Ashley SW. Prospective evaluation of early versus delayed laparoscopic cholecystectomy for treatment of acute cholecystitis. American Surgeon. 2000;66(9):896-900.

17. Knight JS, Mercer SJ, Somers SS, Walters AM, Sadek SA, Toh SK. Timing of urgent laparoscopic cholecystectomy does not influence conversion rate. British Journal of Surgery. 2004; 91(5):6014.

18. Boddy AP, Bennett JM, Ranka S, Rhodes M. Who should perform laparoscopic Cholecystectomy? A 10-year audit. Surgical Endoscopy. 2007;21(9):1492-7. 